\title{
A formação de enfermagem na graduação: uma revisão integrativa da literatura
}

\author{
Undergraduation in the nursing school: an integrative review of literature \\ La formación de enfermería en la graduación: una revisión integral de la literatura
}

\author{
Ariane da Silva Pires ${ }^{I}$; Norma Valéria Dantas de Oliveira Souza ${ }^{\text {II }}$ Lúcia Helena Garcia Penna ${ }^{\text {III }}$; \\ Kelly Fernanda Assis Tavares ${ }^{I V}$; Camila Arantes Ferreira Brecht D'oliveira ${ }^{V}$; Caroline Muller Almeida ${ }^{V I}$
}

\begin{abstract}
RESUMO: Pesquisa bibliográfica na modalidade revisão integrativa da literatura, descritiva e abordagem qualitativa cujo objeto trata da formação de enfermeiros na graduação, considerando os fundamentos que embasam o processo ensino-aprendizagem. Os objetivos foram: caracterizar as abordagens teóricas e metodológicas da produção científica acerca da formação dos enfermeiros e analisar as tendências pedagógicas que norteiam a formação do enfermeiro na graduação. Selecionaram-se sete estudos publicados entre 2008 a 2012. Os dados foram submetidos à análise de conteúdo temática. Com base nesta análise, emergiram duas categorias empíricas - propostas pedagógicas de ensino e mundo do trabalho em saúde e enfermagem; e a formação e o perfil do enfermeiro para o Sistema Único de Saúde: aspectos legais. Evidenciou-se uma forte articulação entre o processo de formação do enfermeiro com sua prática profissional no mundo do trabalho em saúde.

Palavras-Chave: Educação em enfermagem; currículo; trabalho; enfermagem.
\end{abstract}

ABSTRACT: Bibliographic research on the integrative literature review mode; descriptive and qualitative approach whose object is undergraduate education in nursing considering the fundamentals on the basis for the teaching-learning process. The research aimed at [1] characterizing the methodological and theoretical approaches of scientific literature on the training of nurses; and [2] analyzing pedagogical trends in the formation of the nurse on the undergraduate level. Seven studies published from 2008 to 2012 were selected. Data were treated on the basis of thematic content analysis. Two empirical categories emerged out of the analysis: [1] pedagogical proposals in education and work in the health and nursing areas; and [2] training and nurse profile for the SUS (Single Health System): legal aspects. A strong link showed between the nurse's education and their professional practice in the health area.

Keyword: Nursing education; curriculum; work; nursing.

RESUMEN: Investigación bibliográfica en modo de revisión integral de la literatura, enfoque descriptivo y cualitativo cuyo objeto fue la formación de enfermeros en la graduación, teniendo en cuenta los fundamentos que apoyan el proceso de enseñanzaaprendizaje. Los objetivos fueron: caracterizar los enfoques teóricos y metodológicos de la producción científica acerca de la formación de enfermeros y analizar las tendencias pedagógicas que orientan la formación del enfermero en la graduación. Siete estudios fueron seleccionados, todos publicados entre 2008 y 2012. Los datos fueron sometidos al análisis de contenido temático. Basado en este análisis surgieron dos categorias empíricas: propuestas pedagógicas de ensenãnza y mundo del trabajo en salud y enfermería; y la formación y el perfil del enfermeiro para el Sistema Único de Salud: aspectos legales. Mostró un fuerte vínculo entre el proceso de formación del enfermero con su práctica profesional en el mundo del trabajo en salud.

Palabras Clave: Educación em enfermeira; curriculum; trabajo; enfermeira.

\section{INTRODUÇÃO}

O objeto deste estudo é a formação de enfermeiros, considerando os fundamentos que embasam o processo ensino-aprendizagem. Esse objeto emergiu de pesquisa anterior, submetida ao Programa Prociência - Produção Científica, Técnica e Artística da Universidade do Estado do Rio de Janeiro ${ }^{1}$.
O trabalho do enfermeiro não é fácil de ser desenvolvido, considerando que há de se ter habilidades e competências específicas para dar conta da complexidade que envolve o processo laboral da saúde e da enfermagem. Nesse sentido, os enfermeiros precisam de uma formação diferenciada, de alto padrão, pois a

\footnotetext{
'Enfermeira. Mestranda do Programa de Pós-Graduação em Enfermagem da Universidade do Estado do Rio de Janeiro. Bolsista da Fundação de Amparo a Pesquisa do Rio de Janeiro. Brasil. E-mail: arianepires@oi.com.br

IIEnfermeira. Doutora em Enfermagem, Procientista, Professora Permanente do Programa de Pós-Graduação em Enfermagem da Universidade do Estado do Rio de Janeiro. Brasil. E-mail: norval_souza@yahoo.com.br

IIIEnfermeira. Doutora em Ciências dā Saúde. Procientista, Professora Permanente do Programa de Pós-Graduação em Enfermagem da Universidade do Estado do Rio de Janeiro. Brasil. E-mail: luciapenna@terra.com.br

VIEnfermeira. Mestranda do Programa de Pós-Graduação em Enfermagem da Universidade do Estado do Rio de Janeiro. Bolsista da Coordenação de Aperfeiçoamento de Pessoal de Nível Superior. Rio de Janeiro, Brasil. E-mail: kfassis@yahoo.com.br

VInterna do $8^{\circ}$ período da Graduação em Enfermagem da Universidade do Estado do Rio de Janeiro. Bolsista de Iniciação Científica do Conselho Nacional de Desenvolvimento Científico e Tecnológico. Rio de Janeiro, Brasil. E-mail: carolinemulleralmeida@hotmail.com

VIInterna do 8º período da Graduação em Enfermagem da Universidade do Estado do Rio de Janeiro. Bolsista de Iniciação Científica. Rio de Janeiro, Brasil.

E-mail: camilabrechtuerj@gmail.com
} 
própria natureza desse trabalho - o cuidado humano - requer um olhar crítico para a prática e para a formação, demandando capacitação contínua visando garantir qualidade assistencial ${ }^{2}$, traduzida como a satisfação das necessidades do usuário, considerado o objeto central das estratégias e medidas adotadas na busca pela qualidade ${ }^{3}$.

Desse modo, é preciso aludir à complexidade que envolve essa profissão, pois, além de cuidar de vidas humanas - muitas vezes em situação de dor, sofrimento, miséria e morte -, ela também é influenciada pela configuração do serviço de saúde e de enfermagem, os quais são igualmente complexos e fragmentados ${ }^{4,5}$. Portanto, são desafios que devem ser investigados: a formação da enfermagem e a maneira como ela tem contribuído para a construção das competências técnica, científica e ética, para que os enfermeiros cuidem com qualidade, em um contexto laboral frequentemente adverso ${ }^{6}$.

De acordo com o Artigo $3^{\circ}$ das Diretrizes Curriculares Nacionais (DCN), o Curso de Graduação em Enfermagem, de uma forma geral, deve visar a formação do enfermeiro generalista, humanista, crítico e reflexivo. Nessa perspectiva, espera-se que este profissional seja capaz de conhecer e intervir nos problemas e situações de saúde e de doença mais prevalentes no perfil epidemiológico nacional, com ênfase na sua região de atuação, valorizando as dimensões biopsicossociais da vida humana e seus determinantes ${ }^{7}$. Além disso, o enfermeiro que se pretende formar deve ser capacitado a atuar com senso de responsabilidade social e compromisso com a cidadania, como promotor da saúde integral do ser humano ${ }^{8}$.

Este estudo tem relevância à medida que o ensino é compreendido como uma ferramenta básica para a transformação dos processos de trabalho em saúde e educação, dos quais a enfermagem é parte integrante, implicando em uma ressignificação de conceitos e atitudes para produzir uma força de trabalho capaz de atuar de acordo com as exigências e finalidades da profissão ${ }^{9,10}$. Dessa forma, entende-se que o presente estudo possa favorecer e fomentar tal ressignificação.

A fim de apreender o objeto de estudo, traçaram-se os seguintes objetivos: caracterizar as abordagens teóricometodológicas da produção científica acerca da formação dos enfermeiros; e analisar as tendências pedagógicas que norteiam os Cursos de Graduação em Enfermagem.

\section{Metodologia}

Esta pesquisa é de natureza bibliográfica na modalidade revisão integrativa da literatura, portanto foi desenvolvida respeitando-se as seguintes fases: construção da pergunta norteadora; busca ou amostragem da literatura; coleta de dados; análise crítica dos estudos incluídos; discussão dos resultados; e apresentação da revisão integrativa.
A pergunta que norteou a pesquisa foi: o que há de publicado sobre tendências pedagógicas e o processo de formação de enfermeiros?

Para responder à questão norteadora, a pesquisa ocorreu nas bases de dados PubMed, Biblioteca Cochrane, Science Direct, Literatura Latino-Americana e do Caribe em Ciências da Saúde (LILACS), Scientific Electronic Library Online (SCIELO), Base de Dados de Enfermagem (BDENF) e Medical Literature Analysis and Retrieval System Online (MEDLINE), de março a abril de 2013, com os seguintes descritores: enfermagem, educação, currículo e trabalho. Utilizaram-se os descritores tanto isolados quanto combinados com as duas palavras-chave: formação profissional e prática laboral.

Como resultados das buscas, obtiveram-se 4.616 publicações. Excluíram-se 2.578 trabalhos que se encontravam indexados repetidamente nas bases de dados anteriormente citadas. Prosseguindo na busca, acrescentaram-se os seguintes critérios de inclusão: produções científicas nos idiomas Português, Inglês e Espanhol, e recorte temporal de 5 anos (2008-2012). Tal recorte levou em consideração a introdução das novas Diretrizes Curriculares Nacionais do Curso de Graduação em Enfermagem, em 2001, e a formação das primeiras turmas sob essas normas. Após este refinamento, foram encontradas 161 produções. Admitiu-se ainda o critério de inclusão- apenas os textos completos e disponíveis gratuitamente- totalizando, assim, 52 artigos.

Para os critérios de exclusão, foram utilizadas a rejeição de teses e dissertações e a incompatibilidade dos manuscritos com o objeto de estudo. A partir da leitura dos títulos da produção captada e de seus resumos, selecionaram-se nove publicações. Ao proceder a leitura completa desses artigos, identificou-se a incompatibilidade de dois manuscritos, o primeiro porque abordava a ótica da educação permanente em profissionais de enfermagem (auxiliares, técnicos e enfermeiros). Já o segundo, tratava-se de uma publicação em periódico internacional, na língua inglesa, o qual objetivava a construção de um mapa cartográfico do trabalho docente, a partir das mudanças pedagógicas produzidas; entretanto não focalizava o objeto escolhido. Assim, esses dois artigos foram excluídos do corpus de análise.

Ao final do refinamento, apenas sete publicações (uma em espanhol e seis em português) permaneceram para a coleta dos dados. Para tanto, foi elaborado um instrumento próprio, o qual se caracterizou por um questionário contendo as seguintes informações: título dos artigos; ano da publicação; nome dos autores; local do estudo; título da revista em que a obra foi publicada com o volume e o ano; objetivos dos estudos; metodologia aplicada; resultados e conclusão.

A partir do questionário, as informações foram condensadas em forma de figura, facilitando, por um 
lado, a leitura e a identificação de dados relevantes, obtidos a partir da literatura analisada, e, por outro, o estabelecimento da relação entre essas informações e o objeto de estudo. Após o mapeamento das obras, aplicou-se análise temática de conteúdo ${ }^{11}$ e a sistematização temático - categorial ${ }^{12} \mathrm{em}$ todo corpus da produção científica selecionada. Operacionalmente essa técnica é sintetizada em três fases: pré-análise; exploração do material; tratamento dos resultados, inferência e interpretação $0^{11,12}$.

Com base nesta análise, emergiram duas categorias empíricas, as quais foram construídas a partir da junção dos temas com maior incidência na literatura analisada e intituladas como: propostas pedagógicas de ensino e mundo do trabalho em saúde e enfermagem; e a formação e o perfil do enfermeiro para o Sistema Único de Saúde (SUS): aspectos legais. Os dados foram discutidos à luz da literatura sobre o tema ${ }^{1-10,13-30}$.

\section{Resultados e Discussão}

A partir dos sete textos examinados ${ }^{6,17,20,22,23,25,30}$, evidencia-se uma distribuição de artigos, variando entre uma e três publicações por ano, com exceção de 2009, quando não foi identificada produção científica nas bases de dados investigadas. Ver Figura 1.

\begin{tabular}{|c|c|c|c|}
\hline №. & Título & $\begin{array}{c}\text { Autores/Ano } \\
\text { publicação/Periódico }\end{array}$ & Objetivos \\
\hline 01 & $\begin{array}{l}\text { Conocimientos, } \\
\text { habilidades y actitudes } \\
\text { sobre la gestión de los } \\
\text { egresados de enfermería de } \\
\text { una universidad pública } \\
\text { brasileña }\end{array}$ & $\begin{array}{l}\text { Almeida ML, Peres } \\
\text { AM. (2012) } \\
\text { Investigação e } \\
\text { Educação em } \\
\text { Enfermagem }^{25}\end{array}$ & $\begin{array}{l}\text { Identificar nos formandos de uma universidade pública } \\
\text { brasileira os conhecimentos, habilidades e atitudes } \\
\text { aprendidas durante a formação para a gestão em } \\
\text { enfermagem. }\end{array}$ \\
\hline 02 & $\begin{array}{l}\text { Formação em enfermagem: } \\
\text { interface entre as diretrizes } \\
\text { curriculares e os conteúdos } \\
\text { de atenção básica }\end{array}$ & $\begin{array}{l}\text { Silva MJ, Sousa EM, } \\
\text { Freitas CL. (2011) } \\
\text { Revista Brasileira de } \\
\text { Enfermagem }^{30}\end{array}$ & $\begin{array}{l}\text { Analisar Projetos Políticos Pedagógicos dos três Cursos } \\
\text { de Enfermagem mais antigos do Ceará, demonstrando } \\
\text { como as Diretrizes Curriculares Nacionais de } \\
\text { Enfermagem se expressam neles, e as transformações } \\
\text { ocorridas na Enfermagem como profissão no Brasil. }\end{array}$ \\
\hline 03 & $\begin{array}{l}\text { O egresso de enfermagem } \\
\text { da FENF/UERJ no mundo } \\
\text { do trabalho }\end{array}$ & \begin{tabular}{l|} 
Souza NVDO, \\
Correia LM, Cunha \\
LS, Eccard J, Patrício \\
RA, Antunes, TCS. \\
(2011) Revista da \\
Escola de \\
Enfermagem da USP6
\end{tabular} & $\begin{array}{l}\text { Identificar a percepção do egresso de FENF/UERJ sobre } \\
\text { sua atuação e vivência no mundo do trabalho; analisar } \\
\text { tal percepção, depreendendo da mesma, os fatores } \\
\text { causadores de prazer e incômodo aos egressos } \\
\text { decorrentes desta vivência no mundo do trabalho; e } \\
\text { discutir a relação entre os fatores causadores de prazer } \\
\text { e incômodo aos egressos e os propósitos da } \\
\text { reformulação curricular da FENF/UERJ. }\end{array}$ \\
\hline 04 & $\begin{array}{l}\text { Projeto Político } \\
\text { Pedagógico: concepção, } \\
\text { construção e avaliação na } \\
\text { enfermagem }\end{array}$ & $\begin{array}{l}\text { Nóbrega-Therrien } \\
\text { SM, Guerreiro MGS, } \\
\text { Moreira TMM, } \\
\text { Almeida MI. (2010) } \\
\text { Revista Trabalho, } \\
\text { Educação e Saúde } \\
\end{array}$ & $\begin{array}{l}\text { Compreender a formação do enfermeiro com suporte } \\
\text { nos atuais Projetos Políticos Pedagógicos (PPP) dos } \\
\text { cursos de Enfermagem e, especificamente, verificar } \\
\text { junto às coordenadoras e/ou ex-coordenadoras destes } \\
\text { cursos a concepção, construção e avaliação do PPP e a } \\
\text { inserção do sujeito reflexivo como proposta de } \\
\text { formação. }\end{array}$ \\
\hline 05 & $\begin{array}{l}\text { Mudanças na formação e } \\
\text { no trabalho de } \\
\text { enfermagem: uma } \\
\text { perspectiva da educação } \\
\text { popular e de saúde }\end{array}$ & $\begin{array}{l}\text { David HMSL, Acioli } \\
\text { S. (2010) Revista } \\
\text { Brasileira de } \\
\text { Enfermagem }^{20}\end{array}$ & $\begin{array}{l}\text { Refletir a interlocução entre os campos da Educação } \\
\text { Popular, da formação e do trabalho de enfermagem, } \\
\text { apontando para a potencialidade da inserção de } \\
\text { aspetos teórico-metodológicos da Educação Popular } \\
\text { nos processos de formação em enfermagem. }\end{array}$ \\
\hline 06 & $\begin{array}{l}\text { A formação de } \\
\text { profissionais de saúde em } \\
\text { instituições de ensino } \\
\text { superior de Divinópolis, } \\
\text { Minas Gerais }\end{array}$ & $\begin{array}{l}\text { Moraes JT, Lopes } \\
\text { EMT. (2010) Revista } \\
\text { Trabalho, Educação } \\
\text { e Saúde } 23\end{array}$ & $\begin{array}{l}\text { Detectar e avaliar as mudanças na formação dos } \\
\text { profissionais de saúde, mediante a observação do que } \\
\text { ocorre nesse município, além de caracterizar a } \\
\text { formação do profissional de saúde, à luz da legislação } \\
\text { pertinente e com ênfase na política e programas de } \\
\text { saúde pública propostos pelas Diretrizes Curriculares } \\
\text { Nacionais para os cursos de saúde. }\end{array}$ \\
\hline 07 & $\begin{array}{l}\text { O currículo integrado na } \\
\text { Graduação em } \\
\text { Enfermagem: entre o ethos } \\
\text { tradicional e o de ruptura }\end{array}$ & $\begin{array}{l}\text { Opitz SP, Martins JT, } \\
\text { Telles Filho PCP, } \\
\text { Silva AEBC, Teixeira } \\
\text { TCA. (2008) Revista } \\
\text { Gaúcha } \\
\text { Enfermagem }{ }^{17}\end{array}$ & $\begin{array}{l}\text { Refletir sobre o ensino de graduação em Enfermagem, } \\
\text { enfocando o currículo integrado como instrumento } \\
\text { inovador para os professores e os estudantes analisarem } \\
\text { os problemas não só na perspectiva de disciplinas, mas, } \\
\text { também, de outras áreas do conhecimento. }\end{array}$ \\
\hline
\end{tabular}

FIGURA 1: Estado da Arte - distribuição dos estudos examinados, segundo o título, autores/ano de publicação/periódicos e objetivos das pesquisas. 
Em relação às temáticas, os manuscritos abordavam, principalmente: a importância da formação crítica/reflexiva e do currículo integrado, a partir da proposta problematizadora; a construção de um Projeto Político Pedagógico (PPP) em consonância com a Lei de Diretrizes e Bases da Educação (LDB) e das Diretrizes Curriculares Nacionais (DCN); e a reavaliação constante do processo de formação, tanto na perspectiva dos egressos quanto das instituições formadoras. E, em relação ao referencial teóricometodológico, as discussões fundamentaram-se na legislação educacional brasileira, fazendo referência aos modelos socioeconômico e de saúde vigentes no país.

Em relação à abordagem metodológica, observase a predominância de pesquisas qualitativas, do tipo descritivo, incluindo os estudos documentais. Referente aos sujeitos/população, predominaram os enfermeiros (egressos, docentes e coordenadores) e documentos institucionais (PPP e currículo de graduação). Houve dois artigos de reflexão, os quais discutiram a importância do currículo integrado no ensino de graduação em enfermagem e a relação entre os pressupostos da educação popular, a saúde, o trabalho e a formação de enfermagem. Em ambos os artigos de reflexão, as autoras utilizaram seus conhecimentos empíricos para retratar os assuntos abordados.

\section{$1{ }^{\text {a }}$ Categoria: Propostas pedagógicas de ensino e mundo do trabalho em saúde e enfermagem}

Esta categoria analisa dois grandes paradigmas educacionais que fundamentam o processo de formação do enfermeiro: a prática pedagógica tradicional e a prática pedagógica problematiza$\operatorname{dora}^{6,17,20,22,23,25,30}$.

Nessa perspectiva, faz-se relevante caracterizar o modelo de ensino tradicional, pautado na

transmissão de conhecimento compartimentalizado, absolutizado, com práticas de ensino e de avaliação que destacam a memorização e a reprodução de conhecimentos ${ }^{13: 490}$,

corroborando uma formação alienante. Tal formação dificulta que o educando tenha uma visão de integralidade do ser humano, da sociedade e da própria educação.

Os estudos fazem críticas a essa proposta de ensino, destacando a incompatibilidade desse modelo com as demandas do mundo do trabalho e com o sistema de saúde brasileiro. Sabe-se que algumas instituições formadoras têm perpetuado modelos conservadores para a formação dos profissionais de saúde, centrados na orientação biologicista, que concentra o ensino na doença, no tratamento e nas ações de caráter médico. No entanto, essas ações são insuficientes para atender às exigências do modelo sanitário e a complexidade do ser humano saudável ou doente ${ }^{14,17,30}$.
Com a implementação do SUS, houve alterações na organização das práticas de atenção e de gestão do sistema de saúde, estas modificações ocorreram mediante a formulação e ampliação de propostas de novos modelos assistenciais, que acabaram envolvendo a diversificação dos serviços de saúde, os processos de qualificação dos trabalhadores e a natureza do trabalho em saúde. Evidenciando assim, a necessidade de paradigmas inovadores que norteassem a formação dos profissionais da área ${ }^{15,16}$.

Destaca-se que

o processo ensino-aprendizagem desenvolvido no âmago das universidades exerce um papel social de importância ímpar, pois é por meio deste que se determinam as transformações no sistema social, político, econômico e cultural da sociedade ${ }^{17: 315}$.

A educação poderá se diferenciar da educação tradicional quando o professor valorizar as experiências e saberes dos alunos durante as aulas e no ato de ensinar, tornando-se, assim, um facilitador da aprendizagem $^{18}$. Ou seja, a relação entre educador e educando deve ser mediada pelo diálogo e pelo respeito entre ambos: "ninguém educa a si mesmo, os homens se educam entre si, mediatizados pelo mundo"19:39.

A proposta problematizadora, baseada nos pressupostos de Paulo Freire, configura-se num caminhar para consolidação de uma educação crítica, dialética, que seja capaz de tornar o estudante um sujeito ativo no processo de ensino-aprendizagem, reconhecendo seus potenciais, a partir de suas características e história de vida, no contexto socioeconômico e cultura $^{17,19,20,22,23,25,30}$. Nessa perspectiva, tornam-se facilitadas as condições para que esse profissional possa transformar a realidade do trabalho em saúde ${ }^{1}$ e a da enfermagem, as quais se desenvolvem em instituições que possuem organizações laborais engessadas, fragmentadas, pouco racionais e muito complexas.

As instituições que empregam a metodologia problematizadora devem ser pautadas nos seguintes princípios: dialogar com o outro; ter como ponto de partida do processo pedagógico o saber anterior das pessoas, acreditando que todos têm um conhecimento a partir de suas vivências; dar atenção e viabilizar momentos de troca de experiências e de construção de conhecimento entre o saber técnico e o saber popular, o que pressupõe que os diversos saberes são apenas diferentes, e não hierarquizados, e que a experiência vale tanto quanto a teoria ${ }^{20,22,23,25,30}$.

Outros aspectos relevantes foram as questões do trabalho e da formação profissional, as quais, apesar de terem dimensões distintas, estão estreitamente ligadas ${ }^{20,21}$. "Na enfermagem observamos que a formação esteve predominantemente articulada ao mundo do trabalho"22:680.

Assim, no Brasil, desde o início dos anos 1980, vem-se consolidando uma compreensão do processo saúde-doença e do próprio conceito de adoecimento, 
atrelado, a fatores biológicos, políticos e socioeconômicos, os quais se cristalizaram na Constituição de 1988, o que foi

estimulado pelas políticas públicas de saúde e premido pelas necessidades sociais, adequandose a um novo perfil do profissional de saúde que começou a ser desenhado $23: 436$.

A universidade vive então um momento de transformação efetiva, pois formar recursos humanos com perfil adequado às necessidades sociais é o seu grande desafio e implica propiciar aos alunos a capacidade de aprender a aprender, o que não combina com a formação tradicional ou com a pedagogia de transmissão, ainda tão presente nas universidades ${ }^{23}$.

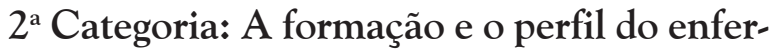 meiro para o SUS: aspectos legais}

Esta categoria discute elementos que envolvem o processo de formação do enfermeiro na sociedade brasileira: LDB, DCN, PPP e currículo integrado, como alicerces para a sustentação de uma proposta pedagógica em consonância com o SUS 6,17,20,22,23,25,30.

A LDB no 9.394, de 20 de dezembro de 1996, estabelece as diretrizes e bases da educação nacional, que se configurou em um novo paradigma para a formação. Na enfermagem, mais especificamente, tem-se as Diretrizes Curriculares Nacionais para a graduação em enfermagem (DCN/ENF), cujo ideal é a flexibilização curricular, com vistas a possibilitar uma sólida formação de acordo com o estágio do conhecimento desenvolvido em cada área, permitindo ao graduado enfrentar as rápidas mudanças na área da saúde e seus reflexos no mundo do trabalho ${ }^{24}$.

No âmbito da formação profissional, as DCN norteiam o ensino de enfermagem para as necessidades do SUS, ao recomendar que o enfermeiro deve ser capaz de conhecer e intervir sobre os problemas e situações de saúde-doença mais prevalentes no perfil epidemiológico nacional, com um perfil generalista, humanista, crítico-reflexivo, com rigor científico e intelectual, pautado nos princípios éticos ${ }^{25}$.

Os estudos analisados apontam a importância das DCN/ENF, aprovadas em 2001, que desencadearam um movimento de reestruturação dos currículos, buscando adequá-los às novas exigências profissionais. Nesse contexto, ocorrem reformas curriculares nas universidades de todo Brasil 6,17,20,22,23,25,30. Além disso, emerge a "preocupação com a solidariedade e a cidadania, com o saber conviver, com o aprender a ser e o aprender a viver com o outro"26:403, como condições elementares que constituem a essência do humanismo e da ética como agentes propulsores do comportamento humano.

Já o PPP surge como principal instrumento político e técnico de balizamento curricular para nível universitário, que deve ser elaborado de forma coletiva no âmbito da instituição. Essa elaboração participativa proporciona ao PPP a particularidade de orientação para cada universidade, como um todo, sendo singular para cada curso de graduação. Ele apresenta uma ação intencional que deve ser definida coletivamente, como consequente compromisso coletivo ${ }^{27}$.

Aludem-se aspectos relevantes em relação tanto à importância dessa construção coletiva quanto às dificuldades que permeiam esse processo de construção. Nesse contexto, o PPP deve expressar uma tentativa de comunicação, de interação dos aspectos subjetivos e objetivos, de reflexividade e de criatividade, cujo desencadeamento depende da iniciativa e envolvimento dos sujeitos implicados nesse processo como coletividade em ação. Parte-se, assim, de um processo interativo-colaborativo, fundamentado na racionalidade e na integração dos saberes pertinentes ao con-

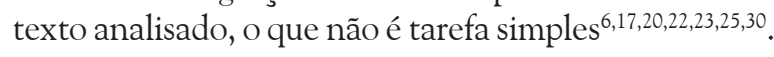

No entanto, não são fáceis nem a construção e nem a implantação desse projeto colaborativo, se for entendido que

nele está o caminho para uma formação pautada no preparo profissional com elementos profissionais competentes, transformadores, reflexivos e condutores da reflexão-na-ação ${ }^{22: 681}$.

Há algumas maneiras de formar profissionais tecnicamente competentes e com capacidade de atender às reais necessidades da população, sendo uma das quais a elaboração de projetos pedagógicos flexíveis, que levem em consideração as regiões, os traços culturais, socioeconômicos e políticos e identidades institucionais e pessoais ${ }^{17}$.

Menciona-se a necessidade de consonância entre o PPP e a flexibilidade dos currículos de graduação, inclusive prevista em lei. Nessa nova ordem nacional, não mais se preconizam os currículos mínimos, com modelo fundamentado por disciplinas e carga horária, mas cria-se a possibilidade de os cursos de graduação implementarem projetos pedagógicos que possam considerar os novos modelos da sociedade ${ }^{28}$.

Nessa mesma linha de pensamento, o currículo deve ser elaborado a partir de uma visão sociopolítica, a qual consiste em compreender que o mesmo é um mecanismo essencial para a constituição de identidades individuais e sociais, na qual interferem relações de poder $^{29}$.

Relacionando as particularidades do mundo do trabalho contemporâneo e o estabelecimento das diretrizes curriculares que fornecem as bases filosóficas, conceituais, políticas, metodológicas e que definem um conjunto de habilidades e competências das diferentes áreas de conhecimento, tem-se a oportunidade de ultrapassar os limites que colocavam uma distância entre o que se esperava da educação e o que ela, efetivamente, pode realizar $6,17,20,22,23,25,30$. 
Nesse contexto, o currículo integrado emerge com uma proposta inovadora, que implica uma nova visão de estudantes como sujeitos ativos, reflexivos, criativos e solidários. Propõe-se ainda favorecer tanto uma relação teórico-prática quanto a compreensão mais global dos problemas, na busca de solução para os mesmos ${ }^{17}$. Dessa maneira, apresenta-se como um instrumento fundamental para a construção do saber reflexivo, sendo um facilitador do processo ensinoaprendizagem.

No entanto, faz-se imprescindível o acompanhamento das propostas pedagógicas e metodologias de ensino adotadas, avaliando, por um lado, sua compatibilidade com as DCN, e, por outro, a maneira como essas práticas pedagógicas estão sendo compreendidas e implementadas dentro das instituições que formam enfermeiros ${ }^{30}$.

\section{CONCLUSÃO}

Por meio deste estudo de revisão, pode-se conhecer um pouco mais dos aspectos que permeiam a formação do enfermeiro e seu processo ensino-aprendizagem. No entanto, compreende-se que esse processo de formação é um fenômeno muito maior do que os aspectos que foram explorados e discutidos na literatura científica analisada.

Da análise dos manuscritos, pode-se concluir que há uma forte influência do processo de formação do enfermeiro em sua prática profissional no mundo do trabalho em saúde, uma vez que seus conhecimentos, habilidades e competências (perfil profissional) são constituídos a partir da formação na graduação. A forma como ocorre esse processo pode gerar consequências positivas ou negativas, tanto para o profissional quanto para a qualidade da assistência em saúde prestada por ele.

Destacam-se também as rápidas transformações que ocorrem na sociedade contemporânea, impondo desafios que demandam maior qualificação e reflexão crítica dos profissionais de enfermagem, para a superação, por parte das instituições formadoras, da dicotomia entre teoria e prática. É preciso valorizar um processo pedagógico problematizador, libertador, que proporcione ao profissional formado uma visão holística do ser humano e de sua sociedade objetivando intervir em suas problemáticas.

Evidencia-se, por fim, a necessidade de aprofundamento da temática, assim como a investigação de novos objetos de estudo; recomenda-se, assim, o estudo do nível de satisfação de graduados em relação ao processo de formação. Sugerem-se também estudos em que as instituições formadoras investiguem se o processo de formação é coerente com o perfil profissional almejado nas DCN e com as demandas da sociedade brasileira.

\section{REFERÊNCIAS}

1.Souza NVDO. O egresso de enfermagem no mundo do trabalho: contribuições para a organização e o processo de trabalho em saúde e enfermagem [Programa Prociência] Rio de Janeiro: Universidade do Estado do Rio de Janeiro; 2011.

2.Matos E. Novas formas de organização e aplicação na enfermagem: limites e possibilidades [dissertação de mestrado]. Florianópolis (SC): Universidade Federal de Santa Catarina; 2002.

3.Vituri DW, Matsuda LM. Validação de conteúdo de indicadores de qualidade para avaliação do cuidado de enfermagem. Rev esc enferm USP [internet] 2009 [citado em 15 ago 2014]; 43: 429-37. Disponível em: http://www.scielo.br/pdf/reeusp/v43n2/a24v43n2.pdf. 4.Cunha LS. As adaptações e improvisações no trabalho hospitalar e suas implicações na saúde do trabalhador de enfermagem [dissertação de mestrado]. Rio de Janeiro: Universidade do Estado do Rio de Janeiro; 2010.

5.Antunes R. Adeus ao trabalho? Ensaios sobre as metamorfoses e a centralidade do mundo do trabalho. $14^{\mathrm{a}} \mathrm{ed}$. São Paulo: Cortez; 2011.

6.Souza NVDO, Correia LM, Cunha LS, Eccard J, Patrício RA, Antunes TCS. O egresso de enfermagem da FENF/ UERJ no mundo do trabalho. Rev esc enferm USP [internet] 2011 [citado em 10 abr 2014]; 45: 250-7. Disponível em: http://www.scielo.br/pdf/reeusp/v45n1/35.pdf.

7.Correia LM, Henriques RLM, Nogueira MFH, Pacheco SA, Romano RT. Construção do projeto político pedagógico: experiência da Faculdade de Enfermagem da UERJ. Rev Bras Enferm [internet] 2004 [citado em 28 mai 2014]; 57: 649-53. Disponível em: http://www. scielo.br/pdf/reben/v57n6/a02.pdf.

8.Ministério da Educação (Br). Conselho Nacional de Educação. Resolução CNE/CES n ${ }^{\circ}$ 3, de novembro de 2001. Institui Diretrizes Curriculares Nacionais do Curso de Graduação em Enfermagem [internet]. Brasília (DF): CNE; 2001 [citado em 29 abr 2014]. Disponível em: http://portal.mec.gov.br/cne/arquivos/pdf/CESO3.pdf.

9.Ito EE, Peres AM, Takahashi RT, Leite MMJ. O ensino de enfermagem e as diretrizes curriculares nacionais: utopia x realidade. Rev esc enferm USP [internet] 2006 [citado em 11 abr 2014] 40: 570-5. Disponível em: http:// www.scielo.br/pdf/reeusp/v40n4/v40n4a16.pdf.

10.Pires D. A enfermagem enquanto disciplina, profissão e trabalho. Rev Bras Enferm. [internet] 2009 [citado em 25 ago 2014]; 62: 739-44. Disponível em: http://www. scielo.br/pdf/reben/v62n5/15.pdf.

11.Bardin L. Análise de conteúdo. Tradução de Luis Antero Reto e Augusto Pinheiro. São Paulo: Livraria Martins Fontes; 2011.

12.Oliveira DC. Análise de conteúdo temático-categorial: uma proposta de sistematização. Rev enferm UERJ [internet] 2008 [citado em 25 ago 2014]; 16: 569-76. Disponível em: http://www.facenf.uerj.br/revista/v16n4/ v16n4a19.pdf.

13.Backes VMS. O processo de ensinar-aprender e seus reflexos na enfermagem. São Paulo: Hucitec; 2005. 
14.Ceccim RB, Feuerwerker LCM. Mudança na graduação das profissões de saúde sob o eixo da integralidade. Cad Saúde Pública. [internet] 2004 [citado em $10 \mathrm{abr}$ 2014]; 20:1400-10. Disponível em: http://www.scielo.br/ pdf/csp/v20n5/36.pdf.

15.Costa RKS, Miranda FAN. Formação profissional no SUS: oportunidades de mudanças na perspectiva da estratégia de saúde da família. Trab Educ Saúde [internet] 2009 [citado em 10 abr 2014] 6: 503-17. Disponível em: http://www.scielo.br/pdf/tes/v6n3/06.pdf.

16.Corbellini VL, Santos BRL, Ojeda BS, Gerhart LM, Eidt OR, Stein SC, et al. Nexos e desafios na formação profissional do enfermeiro. Rev Bras Enferm. [internet] 2010 [citado em 25 ago 2014]; 63: 555-60. Disponível em: http://www.scielo.br/pdf/reben/v63n4/09.pdf.

17.Optiz SP, Martins JT, Telles Filho PCP, Silva AEBC, Texeira TCA. O currículo integrado na graduação de enfermagem entre o ethos tradicional e o de ruptura. Rev Gaúcha Enferm. [internet] 2008 [citado em 15 abr 2014]; 29: 314-9. Disponível em: http://seer.ufrgs.br/index.php/ RevistaGauchadeEnfermagem/article/view/5598/3207.

18.Freire PR. Política e educação. São Paulo: Cortez; 1993. 19.Freire PR. Pedagogia do oprimido. 29a ed. São Paulo: Paz e Terra; 2000.

20.David HMSL, Acioli S. Mudanças na formação e no trabalho de enfermagem: uma perspectiva da educação popular e de saúde. Rev Bras Enferm. [internet] 2010 [citado em 12 abr 2014]; 63: 127-31. Disponível em: http://www.scielo.br/pdf/reben/v63n1/v63n1a21.pdf. 21.Silva DGV. Souza SS, Trentini M, Bonetti A, Mattosinho MMS. Os desafios enfrentados pelos iniciantes na prática de enfermagem. Rev esc enferm USP [internet] 2010 [citado em 25 ago 2014]; 44: 511-6. Disponível em: http://www.scielo.br/pdf/reeusp/v44n2/38.pdf.

22.Nóbrega-Therrien SM, Guerreiro MGS, Moreira TMM, Almeida MI. Projeto político pedagógico: concepção, construção e avaliação na enfermagem. Rev esc enferm USP [internet] 2010 [citado em 28 mai 2014]; 44: 679-86. Disponível em: http://www.scielo.br/pdf/ reeusp/v44n3/18.pdf.

23.Moraes JT, Lopes EMT. A formação de profissionais de saúde em instituições de ensino superior de Divinópolis, Minas Gerais. Trab Educ Saúde [internet] 2009 nov [citado em 28 mai 2014]; 7: 435-44. Disponível em: http:// www.revista.epsjv.fiocruz.br/upload/revistas/r264.pdf. 24.Ministério da Educação (Br). Instituto Nacional de Estudos e Pesquisas Educacionais Anísio Teixeira. $\mathrm{O}$ ensino de enfermagem no Brasil: o ontem, o hoje e o amanhã. Brasília (DF): Ministério da Educação; 2006. 25.Almeida ML, Peres AM. Conhecimentos, habilidades e atitudes sobre a gestão dos formados de enfermagem de uma universidade pública brasileira. Invest Educ Enferm [internet] 2012 [citado em 28 mai 2014]; 30(1): 66-76. Disponível em: http://aprendeenlinea.udea.edu.co/revistas/index.php/iee/article/view/7823/10514.

26.Ribeiro JP, Tavares M, Esperidião E, Munari DB. Análise das diretrizes curriculares: uma visão humanista na formação do enfermeiro. Rev enferm UERJ 2005; 13: 403-9. 27.Veiga IPA. Projeto político-pedagógico da escola: uma construção possível. 10 ${ }^{\mathrm{a}} \mathrm{ed}$. Campinas (SP): $\mathrm{Pa}$ pirus; 2000.

28. Ministério da Educação (Br). Portaria n 646, de 14 de maio de 1997. Regulamenta a implantação do disposto nos artigos 39 a 42 da Lei Federal no 9.394 e no Decreto Federal n 2.208/97 e dá providências. Brasília (DF): CFE; 1997.

29.Moreira AFB, Silva TT, organizadores. Currículo, cultura e sociedade. Tradução de Maria Aparecida Baptista. 6a ed. São Paulo: Cortez; 2002.

30.Silva MJ, Sousa EM, Freitas CL. Formação em enfermagem: interface entre as diretrizes curriculares e os conteúdos de atenção básica. Rev Bras Enferm [internet] 2011 [citado em 10 abr 2014]; 64: 315-21. Disponível em: http://www.revista.epsjv.fiocruz.br/upload/revistas/r84.pdf. 